\title{
La verdad tras el discurso Formación profesional en el nuevo milenio
}

\author{
Marcos Ruiz Ruiz \\ Universidad de Lima
}

Recibido: 20/ 1/2011

Aceptado: 6/2/2011

\begin{abstract}
Resumen: ¿Dónde está la verdad que todo profesional debe buscar? ¿Cómo identificarla y aprender a distinguirla de posibles falacias? ¿Qué relación guarda con el discurso económico y liberal del siglo XXI? ¿Hasta qué extremo los valores de los nuevos tiempos pueden afectar las estructuras más íntimas de la formación profesional universitaria? ¿Hay esperanza de salida, o la profesionalización está sojuzgada por mecanismos de control inadvertidos? En el siguiente texto ensayaremos una aproximación a estos cuestionamientos, centrándonos en las ingenierías y los negocios, campos profesionales que son agentes de indiscutible desarrollo para la sociedad.
\end{abstract}

Palabras clave: Verdad / formación profesional / control / discurso

\section{The truth behind the discourse \\ Vocational training in the new millennium}

Summary: Where is the truth that every professional must seek? How do we identify it and learn to separate it from possible errors? How is it related to the economic and liberal discourse of the Twenty-first century? How far do the values of the new times affect the most elemental structures of a professional university preparation? Is there hope for an exit or is professional training subjugated by unforeseen control mechanisms? Below, we will attempt to answer these questions, focusing on the different branches of engineering and business, professional fields that are the foundation for indisputable development for society.

Keywords: Truth / vocational training / control / discourse 
No basta decir solamente la verdad, más conviene mostrar la causa de la falsedad.

Aristóteles

\section{Verdad y discurso}

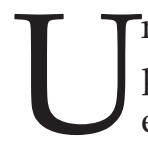

n imperativo que tenemos los profesores universitarios -no exclusivo de nuestra "especie", por cierto- es cuestionarnos sobre el sentido de la verdad, sobre su naturaleza y los complejos mecanismos sociales y espacio-temporales que acompañan su evolución. Un imperativo aún más importante resulta el proceso de motivación en nuestros estudiantes hacia la búsqueda objetiva de ella; despertando una conciencia autónoma y libre de cualquier tipo de prejuicio o alienación. En este esfuerzo, a más de uno puede haberle surgido una suerte de desazón al encontrarse en una aporía o, peor aún, un desencanto al intuir vinculada a la verdad difundida- mecanismos subliminales y complicados de poder que recubren de aparente sentido de verdad intereses subalternos, ideologías mesiánicas o discursos racionalmente estructurados que se presentan como verdades absolutas, insoslayables e incluso necesarias para sobrevivir.

Resulta imprescindible advertir que el sentido de verdad al que me refiero va más allá de la validación de contenidos curriculares o de la certeza de una hipótesis científica. El sentido de verdad que es materia de preocupación personal, está asociado a la autenticidad de la función educativa y a la pertinencia de la formación profesional (¿acaso deformación en algunos casos?) que sirve de plataforma a nuestros estudiantes para su maduración a lo largo de los años universitarios; preparándolos para la vida y para su inserción en los complejos mecanismos de relación política, social y económica.

La verdad, reconocida bajo esta dimensión, apunta más hacia el logro de la coherencia personal entre la praxis y el discurso; hacia un proceso de autorreconocerse como persona capaz de un nítido discernimiento entre el bien y el mal y de la trascendencia de su libertad. Un proceso que finalmente me ubica como parte integrante de una comunidad en la que debo aprender a evolucionar del "yo individualista" al "nosotros solidario". ${ }^{1}$ Esa verdad (honestidad, integridad, dirían otros) está ligada a una autonomía que permite no solo reconocer aquello que no es conveniente para los fines personales trascendentes del hombre, sino, principalmente, aquello que bajo el discurso de "verdad absoluta" se presenta como un camino ineludible y único para el desarrollo personal y colecti-

1 No es posible hablar de solidaridad sin entender, de una vez por todas, la importancia de la equidad y la justicia social que otorguen un mínimo de decencia moral a una sociedad. 
vo. El educador, como responsable del acompañamiento del joven, debe ayudarle a entender que los discursos se nos presentan muchas veces contaminados por factores culturales, históricos, políticos o económicos. Una recta conciencia tiene que ver más con una concordancia con la norma áurea cristiana de amar al prójimo como a uno mismo que con imperativos morales que se adaptan, no en todos los casos por cierto, a criterios consensuados e interesados de pequeños grupos de poder y de control.

Con lo anterior se desprende el sentido de la necesidad de una formación sobre la base de la verdad. Esto, sin embargo, no resulta tan sencillo de entender y menos aún de llevar a la práctica por la problemática que el entorno puede presentar. Uno de los principales problemas que inunda el quehacer educativo superior es el manejo de fórmulas racionales y esquemas que se presentan como claves absolutas de verdad que no podemos evitar. Educadores y alumnos nos vemos sometidos a una secuencia racional de procedimientos que deben ser aceptados -por ejemplo- en bien de la llamada eficiencia y calidad educativa de la formación profesional. Algunos se someten con más facilidad a los planteamientos y exigencias de "esas verdades" que otros, o caen en lo que se llama una "inercia de esfuerzo racional" que lleva a mantener simplemente el statu quo. No se trata de negar la necesidad de pautas y criterios generales. Tampoco la necesidad de una estructura ordenada y sistematizada, en la medida en que esta respete ampliamente la ética del consenso y su fórmula sea tomada como lo que es: un intento en el tiempo y el espacio que merece (y necesita) ser sometido a continua reflexión, crítica y revisión. Lo importante para el educador y el estudiante es hurgar qué mecanismos de poder o qué discursos interesados pueden esconderse bajo una $\mathrm{u}$ otra propuesta, a efectos de aceptarla o rechazarla ideológicamente en su verdadera dimensión. A partir de la premisa de la inexistencia de fórmulas de verdad absoluta, hay que tener presente la clásica diferenciación de Kant entre "la cosa en sí" y la "cosa para mí". ${ }^{2}$ En esta línea, la verdad, según el biólogo y filósofo Humberto Maturana, no puede ser absolutizada ya que lo dicho es siempre dicho por un observador que no puede reclamar un acceso privilegiado a una verdad o realidad externa. Asimismo,

2 Uno de los aportes más importantes de la filosofía de Kant reside en la diferencia entre "das Ding an sich" y "das Ding für mich" (“la cosa en sí" y “la cosa para mí”) según la cual pretende advertir que no podemos saber cómo son las cosas realmente, sino solo cómo aparecen circunstancialmente ante nosotros. 
[...] el que piensa que sus supuestos son verdaderos en un sentido absoluto, comete un error decisivo: confunde creer con saber, y se atribuye por lo tanto cualidades que como ser vivo simplemente no puede tener (Maturana y Pörksen 2005).

Quiero advertir que no se pretende que el educador propugne una "verdad a gusto del cliente". Empero, es muy necesario que este se manifieste abiertamente crítico frente a los esquemas totalizantes o fundamentalistas que pueden dificultar una convivencia basada en el respeto, la tolerancia y el consenso democrático. Solo así los estudiantes pueden ser herederos de una conciencia crítica y reflexiva. Los meros contenidos curriculares, sin minusvalorar su importancia, quedan en un segundo plano cuando llegamos al fondo mismo del sentido educativo. En el proceso de formación, es conocido que el influjo es de centro a centro personal y que educamos antes con nuestras maneras y actitudes que con nuestros discursos teóricos. Lo señala Fernando Savater cuando afirma que:

[...] lo propio del hombre no es tanto el mero aprender como el aprender de otros hombres, ser enseñado por ellos. Nuestro maestro no es el mundo, las cosas, los sucesos naturales, ni siquiera ese conjunto de técnicas y rituales que llamamos cultura, sino la vinculación intersubjetiva con otras conciencias (Savater 1997).

Esa realidad social intersubjetiva es precisamente la que puede con- vertir la verdad en una coincidencia y acierto en el tiempo y el espacio. Ese carácter de relatividad hace a la verdad merecedora de un humilde análisis interpretativo y crítico que acepte de una vez por todas que solo existen aproximaciones a la realidad. La verdad es una cualidad de nuestro intento de acercarnos al mundo pero no es una cualidad propia del objeto aprehendido. Como explica Savater, no hay verdad solo en quien conoce o solo en lo conocido, sino en una correspondencia entre ambos. La verdad será verdad en un aquí y ahora que no puede absolutizarse, porque

[...] no hay verdad en términos absolutos, lo mismo que no hay izquierda o derecha absolutas (hablo de topología, no de política), sino siempre respecto a algo y de acuerdo con determinada orientación (Savater 2003).

Sin embargo, dicha verdad no deja de ser menos verdad. He aquí la diferencia entre una verdad que se propugna como relativa, frente a una relativizada que se entiende como menos verdadera de lo que debería ser. En el campo moral, ya lo señala con más autoridad el jesuita Xavier Melloni cuando estudia la interrelación cultural y religiosa en búsqueda de una verdad ecuménica teologal:

El relativismo implica la equiparación anodina de valores, creencias y cosmovisiones, donde todo vale y nada nos compromete; mientras que la relatividad comporta la percepción de que todo está relacionado con todo, 
y ninguna cultura y ninguna religión se pueden aislar de este contexto (Melloni, en línea).

Al margen de disquisiciones filosóficas en torno a la naturaleza y al alcance relativo (no relativista) de un discurso que se aproxima como fórmula de verdad, resulta más importante por ahora seguir un ensayo de búsqueda de los mecanismos de poder subyacentes a este.

La verdad y el poder, ya lo señalaba el crítico francés Michel Foucault, guardan una íntima propiedad relacional y se manifiestan de formas más o menos evidentes en las sociedades occidentales modernas a través de los discursos.

Por verdad hay que entender un conjunto de procedimientos reglados por la producción, la ley, la repartición, la puesta en circulación, y el funcionamiento de los enunciados. La verdad está ligada circularmente a los sistemas de poder que la producen y la mantienen, y a los efectos de poder que induce y que la acompañan, al régimen de verdad (Foucault 1999).

En tal sentido, muchos de estos discursos que han acompañado el desarrollo de la actual economía de mercado han calado profundamente en las relaciones dentro de la organización empresarial y también en las estructuras más intimas de la vida académica. El discurso neoliberal puede presentarse entonces como una fórmula peligrosamente asimilada que no advierte de ciertos peligros. No tanto en el sen- tido de implicancias económicas para un Estado, sino en cuanto a la ceguera reflexiva del currículo que empieza a reorientar la formación profesional de nuestros estudiantes bajo esquemas de relación poder-verdad que no se detectan. Es precisamente en este aspecto donde vale la pena denunciar el riesgo que todo ello puede acarrear.

Mucho se ha hablado del proceso de globalización propio de la llamada posmodernidad. Muchos han alabado sus bondades y advertido de sus nefastas consecuencias. Por eso, se procurará mantener una posición que respete el justo medio escolástico para una reflexión serena y desapasionada del tema. Siguiendo el rumbo estructurado líneas arriba, la perspectiva de análisis se centrará por ahora en una crítica a la verdad que esconde el discurso de la globalización social y económica en el ámbito académico y en la formación profesional.

\section{Los nuevos valores}

El modelo económico neoliberal, según Alejandro Saavedra (2006), tiene tres aspectos fundamentales que vale la pena citar a fin de entender el contexto en el que las universidades deben formar a los profesionales para el "nuevo milenio". El primer aspecto es la consolidación de una economía caracterizada por la interdependencia de sus actores. Es decir, la unificación económica que implica repercusiones de todo en todo. Un modelo que se 
presenta como único y ante el cual “[...] cada uno debe esforzarse por integrarse so pena de desaparecer" (Savater 2006: 69). Hasta la caída del comunismo en Europa, los propulsores del liberalismo concebían que los países "subdesarrollados" debían alcanzar el nivel de vida de los países altamente industrializados en todo ámbito (económico, político, social y cultural). La nueva propuesta presenta el desarrollo como una integración ineludible y de hecho. No queda como alternativa su rechazo, ya que ella nos condenaría a la eterna exclusión y al ostracismo social. El segundo aspecto es quizás el más visible y el que más implicancias puede traer al ámbito educativo de forma indirecta. Se trata de la modificación de las formas de producción en un esfuerzo por la "[...] búsqueda desaforada de mayores utilidades de la productividad" (Savater 2006: 70). Este aspecto se vincula con los revolucionarios avances tecnológicos -especialmente en el campo de las TIC- a los que hemos asistido en los últimos años y que, sin lugar a dudas, continúan sorprendiéndonos. Dichos avances han generado en algunos casos beneficios importantes, pero también desplazamiento de las masas sociales hacia el desempleo o subempleo. En este escenario, la empresa (ahora transnacional y globalizada) busca instalarse en países que ofrezcan la máxima estabilidad política y social, para producir con bajos salarios. Solo así logrará la mayor rentabilidad y acumulación de capital, aún en detri- mento de consideraciones sociales por demás conocidas. Aquí cabe hacer una reflexión en torno a la importancia de la capacitación técnica y profesional de la juventud, que tiene que sobrevivir en un entorno cada vez más competitivo. En el contexto globalizado no hay opción cuando de capacitación técnica o profesional se trata si deseamos adaptarnos al sistema imperante. Finalmente, y como tercer aspecto, se encuentra el rol del Estado que se convierte, bajo la presión del mercado, en una suerte de monstruo pesado y parásito para el libre desarrollo.

Bajo este panorama, penetra en la sociedad junto al discurso posmoderno, una nueva escala de valores frente a los cuales hay que guardar una prudente distancia de reflexión. Los nuevos valores son ahora la competitividad, la calidad, la privatización, el consumismo para el bienestar, la eficiencia, la productividad, etcétera. Como es de suponer, el mundo académico no es ajeno a este giro copernicano. La formación profesional debe "amoldarse" a estos nuevos esquemas donde -a manera de ejemplo con una dosis de sarcasmo- los ingenieros y administradores deben aprender más de sistemas productivos eficientes $y$ calidad total que de antropología filosófica. Así, incluso el sentido ontológico de la misma educación sufre una metamorfosis. Lo decía ya con cierta fruición y a su estilo Michael Korda cuando hablaba del poder y su vínculo con la vida educativa: 
Nuestro sistema de educación nos enseña a poner nuestra fe en algo exterior, una empresa, un matrimonio, un comercio, una profesión, una religión, la política, algo -casi podríamos decir cualquier cosa- que nos ofrezca un conjunto de reglas que podamos obedecer y que obtengamos recompensa por obedecerlas. Es más seguro ser un animal doméstico que salvaje (Korda 1977).

No es de extrañar pues que las carreras profesionales con mayor demanda sean aquellas que permiten a los nuevos profesionales adaptarse mejor a este esquema posmoderno. No es de extrañar tampoco que el mundo de la gestión educativa se encuentre constantemente enfrentado a dilemas sobre cómo, qué y para quién educar. En más de una ocasión ha surgido el cuestionamiento en torno a si, por ejemplo, los centros de educación superior deben ofrecer carreras profesionales que "respondan mejor a las exigencias del mercado" o deben ser más honestos con la ineludible responsabilidad social que les asiste y estudiar la posibilidad de ofrecer carreras que, si bien tienen poca demanda y deben ser incluso subvencionadas, resultan una necesidad. Esto permitiría la formación de profesionales en otras áreas del conocimiento (quizás más vinculadas a las humanidades), que garanticen una sociedad más equilibrada en los próximos años. Una encuesta realizada al término del año 2007 por el Grupo de Opinión Pública de la Universidad de Lima (GOP, en línea) sobre la demanda de profesionales por las empresas de mayor facturación, señala que los tres profesionales más requeridos en el Perú son los ingenieros industriales, los administradores y los contadores. La misma encuesta señala que los profesionales más requeridos en un horizonte de diez años serán también los ingenieros industriales (18\%), los administradores (16\%) y los contadores $(8,8 \%)$. Cabe aquí cuestionarnos si estas tendencias son un imperativo que debe necesariamente marcar el rumbo de formación académica en las instituciones de nivel superior. Al final de cuentas, son los requerimientos que algunos sectores empresariales consideran necesarios para subsistir en la economía mundial a la que hacíamos referencia anteriormente. Hay que ser claros en que el problema no está en continuar o dejar de formar ingenieros o administradores. El problema central radica en cómo formarlos y cómo prepararlos para que, sin dejar de ser competentes en el medio profesional, no renuncien a una búsqueda continua del sentido de verdad al que aludíamos en un comienzo. Más aún en un mundo en que el humanismo y la justicia social como valores están involucionando. En un plano más concreto, cómo formar a nuestros futuros profesionales para que sean conscientes de los mecanismos que subyacen al discurso propio de la economía de mercado y no se pierdan en sus falsas doctrinas ideológicas. Se propugna entonces una revalorización académica de las 
humanidades en la formación de los agentes de cambio del futuro, que les permitan a nuestros jóvenes ser críticos defensores de la justicia social y no incautos instrumentos de la posmodernidad. En definitiva, revalorar la necesidad de formar profesionales críticos frente a los sofismas del discurso. Pero eso no solo depende de los maestros. Depende en principio de un entendimiento cabal de la responsabilidad que las universidades públicas y privadas tienen en sus manos, de la concepción que manejen de la gestión educativa y de la revalorización de las áreas humanistas del conocimiento. El problema es sin duda mucho más complejo, pero no por ello se debe dejar de discutir y reflexionar.

\section{Educación y nuevo milenio}

Centrémonos ahora más en el mundo de la gestión educativa y en todas las dimensiones que encierra, para echar un vistazo a su naturaleza y adaptación al discurso de los "nuevos tiempos". Es probable que, entre todos los nuevos valores de la economía liberal, el que más influencia tenga a nivel de la gestión educativa sea el de la competitividad. Esta nueva ley, que lleva la lógica de que el éxito personal tiene que ser el fracaso del competidor, genera una reconversión radical en las estructuras de la formación académica. El "enemigo" es un rival al que, si no se vence, se debe absorber a fin de seguir dando culto al nuevo dios que todo lo compra y todo lo vende. De esta forma, la calidad, la eficiencia, la orientación casi paranoica por la optimización de resultados finales, va calando poco a poco en la conciencia de los profesores universitarios y sus alumnos. El currículo puede convertirse entonces en un peligroso intento de perpetuar mecanismos políticos y económicos que no favorecen el desarrollo personal y colectivo en otras dimensiones más humanas y trascendentes.

En más de una ocasión, hemos sido testigos de la sobrevaloración que se da al manejo de indicadores orientados al control y optimización de los resultados. Si bien los resultados no dejan de ser importantes, esta concepción que se refleja también a nivel del sistema evaluativo curricular, puede olvidar un principio elemental: el carácter relativo de los avances y de los logros. La comparación debe establecerse contra uno mismo. No es lo óptimo necesariamente alcanzar una media de 20/20 frente a una de $15 / 20$ por el carácter de relatividad que debe guardar todo sistema de evaluación. Quizás la media de 15/20 refleja un desarrollo personal o grupal más significativo en términos de avances y logros. Esto echa por tierra ese absurdo afán de uniformizar la evaluación sobre la base de criterios universales. Más aún si somos conscientes del agravante de que estos criterios son a veces productos impuestos por el sistema imperante y por los valores que arbitrariamente propugna. Habría que preguntarse entonces para quién es la eficiencia lograda, 
para quién es la calidad alcanzada, para quién el resultado esperado. De igual forma, habría que preguntarse si los únicos móviles que subyacen a los nuevos sistemas de acreditación y certificación son los de la competitividad salvaje propia de nuestro contexto posmoderno. ¡Cómo educar entonces a las nuevas generaciones de profesionales sin perder la brújula del imperativo humano por evolucionar!

Sin embargo, no todo es negativo en un mundo globalizado. No es nuestra máxima el nihilismo o un desencanto absoluto por la vida y el futuro. Como bien lo señala Fernando Savater (1997), como educadores

[...] no nos queda más remedio que ser optimistas. [...] Quien no quiera mojarse, debe abandonar la natación; quien sienta repugnancia frente al optimismo, que deje la enseñanza y que no pretenda pensar en qué consiste la educación. Porque educar es creer en la perfectibilidad humana [...].

$Y$ en aras de esa perfectibilidad es que debemos denunciar los riesgos que la ceguera reflexiva puede traer en los esfuerzos por gestionar la educación; especialmente cuando se claudica ante discursos de verdad que no contribuyen a la humanización. Sin embargo, la posmodernidad trae también mayores accesos a la información, mejores vías de comunicación y estándares materiales de vida que, mejor distribuidos, pueden ser dignos de elogio. Trae también a las nuevas generaciones mayores posibilidades de apertura al diálogo, al intercambio y a la movilidad social, así como una revaloración, por parte de las voces más nobles, del respeto por la diferencia y la inclusión en todo campo social y cultural. La tarea es precisamente la canalización de estas ventajas y posibilidades. La educación -como actividad fundamental del desarrollo de una sociedad- tiene que pronunciarse en este sentido (sino acaso, decirlo absolutamente todo).

Retomando el tema de la gestión educativa, esta es la que Michael Foucault llama "tecnología moral" o tecnología de poder. Es toda una tecnología racional que se orienta a la eficiencia, viabilidad y control. Como dice Stephen J. Ball (1997), este proceso de gestión

[...] representa la burocratización de la estructura de control a través de las descripciones de tareas, relaciones lineales de gestión y el establecimiento de flujos determinados de comunicación y un estilo de toma de decisiones similar al propio de las comisiones [...].

Los conceptos y procedimientos de evaluación son tomados de las organizaciones industriales que muchas veces pierden el sentido ontológico del trabajo educativo, y se presentan encerrados en discursos donde los agentes involucrados (directivos, profesores, alumnos, administrativos, etcétera) nos convertimos en medios o instrumentos para un fin particular del sistema predominante. 
La supremacía de este esquema de gestión educativa tiene un efecto en el perfil del nuevo docente requerido, así como del egresado. Los perfiles se van amoldando a los nuevos paradigmas. Estudiantes y egresados en serie, para ser insertados en el competitivo mercado laboral. Aulas con cada vez más alumnos por docente que deben ser "adoctrinados" en los requerimientos sociales de la nueva era. Profesores con amplísima experiencia como gerentes, jefes de producción o directores. El sentido pragmático e inmediato reemplaza los criterios formativos y de largo aliento. El utilitarismo propio del valor de la eficiencia y efectividad se van insertando incluso en los planes de estudios propuestos, que pueden ir sacrificando su esencia ontológica y axiológica propia de la formación profesional. Algunas asignaturas se van considerando "obsoletas" en aras de los nuevos paradigmas que impone el discurso, no tanto por sus contenidos poco actualizados, sino por su poco sentido de utilidad inmediata. La "verdad parcializada" se impone y cada vez formamos más profesionales competitivos, eficientes y preparados para enfrentar un mundo globalizado; pero también con evidentes falencias humanistas que peligrosamente pueden llevarnos a una sociedad infeliz y nada solidaria.

En líneas anteriores hemos reflexionado en torno a la necesidad de una revalorización del sentido humanista y social en toda formación profesional.
El giro no consiste en aumentar las horas teóricas, crear nuevos cursos de ética o filosofía en la malla curricular o atosigar de lecturas -muchas veces poco significativas- a los estudiantes de negocios o de ingeniería. Estamos convencidos de que uno puede enseñar un curso de contabilidad básica, de investigación de operaciones o de física, enseñando al mismo tiempo ética o axiología. ¿Quién cuestionaría que la humanidad se enseña también actualizando las facultades superiores del hombre? De allí que antes de que nuestros alumnos se preocupen por encontrar los ratios financieros o los indicadores de productividad, los maestros debemos lanzarlos al terreno de la crítica y la reflexión sobre su exactitud, sobre la verdad que aparentemente divulgan, sobre sus efectos sociales, etcétera. Insistimos, ¿eficiencia para quién?, ¿para la empresa?, ¿para los trabajadores?, ¿para la sociedad?, ¿para el Estado? También así se humaniza un plan de estudios. Pero eso definitivamente demanda un doble esfuerzo por parte del docente y del estudiante. Un profesional reflexivo y crítico solo es consecuencia de un ejercicio constante de sus capacidades de orden superior. Un profesional instrumentalizado y útil al sistema imperante responde a un proceso de formación profesional carente de estos beneficios.

Entre las estrategias de poder estudiadas por Foucault (1999), el tema del sistema educativo universitario como 
modo de transmisión del saber en una sociedad, salta por su complejidad y poco análisis. El estudiante en formación resulta en un instrumento de la sociedad que, con el afán de mantener su racionalidad y cohesión, se convierte en un paria. La vida universitaria lo conmina al interior de un circuito que posee una doble función. Por un lado, la exclusión dentro del campus universitario -al margen de la vida social- donde es sometido a mecanismos sociales artificiales (relaciones jerárquicas, tribunales de honor, exámenes, rituales de evaluación, entre otros). Y por otro lado -aunque resulte paradójico- se le somete a una función de integración. Es decir, una vez que el estudiante ha culminado satisfactoriamente los años de carrera profesional en esa sociedad artificial, ya es alguien "asimilable". La sociedad (y cuánto más en esta etapa globalizada) ya está listo para consumirlo:

De forma insidiosa [el estudiante universitario] ha recibido los valores de esta sociedad, ha recibido los modelos deseables de conducta, las pautas de ambición, los elementos de un comportamiento político, de tal forma que ese ritual de exclusión termina por adoptar la forma de la inclusión y de la recuperación o de la absorción. En este sentido la universidad es, sin ninguna duda, una institución que se diferencia poco de los sistemas mediante los cuales, en las sociedades llamadas primitivas, se mantiene a los jóvenes al margen del poblado durante la adolescencia, y se les somete a ritos de iniciación que los aíslan y los privan de todo contacto con la sociedad real, con la sociedad activa. Una vez que ese periodo ha transcurrido, ya pueden ser totalmente recuperados o reasimilados (Foucault 1999).

Los programas universitarios que, bajo los condicionamientos del mercado laboral, únicamente se encuentran avocados a la instrucción de nuevos engranajes sociales que persistan y sobrevivan al sistema capitalista o que se esfuercen al máximo por perpetuarlo y mantener las estrategias de poder subyacentes a este, olvidan el principio rector y esencia transformadora social de la universidad. El círculo se vuelve interminable y sin posibilidad de salida. Nuestros jóvenes salen al mercado laboral tentando, en competencia salvaje, una práctica profesional donde muchas veces se les exigen responsabilidades en forma desmedida o son víctimas de explotación. Sus ambiciones se centran luego en un escalamiento laboral y social -acaso recurriendo a todo lo que esté a su alcance para ello- esforzándose por cubrir una plaza vacante de un jefe de área o supervisor, para llegar finalmente a la gerencia. Nuevamente, serán ellos los que demandarán otros practicantes para, bajo la misma fórmula, insertarlos al mundo laboral. De esta manera, algunos de los valores antes mencionados de la economía de mercado se perpetúan y lamentablemente ni estudiantes, ni docentes, ni gestores educativos; y menos aún empresarios, advierten de esta situación para ser 
capaces de revertirla. La convivencia social (en equidad y justicia) se vuelve peligrosamente inmanejable, acentuando la negación de aquella biología del amor que con tanta exquisitez y verdad desarrolla Humberto Maturana:

Si uno entiende lo que es el amor, reconoce inmediatamente cuándo y bajo qué circunstancias el amor es negado. Ve a aquellos padres que permanentemente corrigen a sus hijos, les reprochan distintos errores y los amenazan con castigos. Y percibe las características de nuestra cultura y comprende que la tan alabada competitividad no es una fuente de progreso sino que produce ceguera porque niega al otro. Uno se da cuenta que la ambición y la desconfianza, más el ansia de poder y control culturalmente anclados, son los que hacen desaparecer el amor. La economización de las relaciones -las necesidades se negocian, las concesiones se obtienen y los compromisos se adquieren- destruyen el goce simple de la compañía del otro porque la convivencia está organizada según el modelo del negocio económico (Maturana y Pörsken 2005).

\section{Reflexión final}

La reflexión que faltaría hacer, a la luz de lo anteriormente expuesto, puede tomar como principio rector la prudencia aristotélica recomendada al momento de determinar la bondad de la relación entre medios y fines. La universidad, por un lado, debe a su naturaleza de responsabilidad para con la verdad, el conocimiento y la sociedad, una prudencia en sus decisiones estratégicas y una clara visión de qué profesionales debe formar.

El currículo profesional no debe claudicar ante los nuevos ídolos de la modernidad, pero al mismo tiempo debe tener la capacidad de formar agentes que se adapten al sistema sin renunciar a su esencia transformadora.

Asimismo, le toca fomentar un espacio de apertura y diálogo para la exposición de ideas y de conocimiento, orientados no solo a la búsqueda de la verdad, sino especialmente a la denuncia de aquellos interesados propósitos que se recubren de ella. A los maestros, por nuestro lado, nos corresponde alinearnos también a este proyecto de desarrollo profesional en una recta conciencia moral para la búsqueda de la verdad, sin perjuicio desde luego de las sólidas bases teóricas que todo profesional necesita. También la prudencia nos permitirá ser cautos frente a los discursos y desarrollar, junto a nuestros estudiantes, el sentido crítico y reflexivo que tanto requerimos para humanizar las nuevas generaciones.

Y finalmente, los estudiantes tienen también su cuota de responsabilidad. A ellos les corresponde tener siempre los ojos atentos para entender que ser productivos y competitivos no es la principal razón de ser profesional; y que para entender que no existe verdad sin sentido de justicia y solidaridad, hace falta - parafraseando a un viejo maestro jesuita- aprender a "ver la verdad debajo del agua". Que ese 
sea nuestro compromiso, por el bien de las próximas generaciones y de nuestra sociedad.

\section{Bibliografía}

Aristóteles (1983). Moral a Nicómano. 3. ${ }^{\text {a }}$ edición. Madrid: Espasa Calpe.

BAll, Stephen J. (ed.) (1997). Foucault y la educación. Disciplinas y saber. La gestión como tecnología moral. Madrid: Ediciones Morata.

Cardona, Carlos (2001). Ética del quehacer educativo. Madrid: Rialp.

- (1999). Estrategias de poder. Madrid: Paidós.

Foucault, Michel (2006). La voluntad del saber. Historia de la sexualidad. Tomo I. Buenos Aires: Siglo XXI.

GAArder, Jostein (1994). El mundo de Sofía. Madrid: Siruela.

Grupo de Opinión Pública de la UniVERSIDAd DE Lima (GOP) (setiembre-octubre del 2007). Estudio 380 / Barómetro empresarial / Encuesta sobre demanda de profesionales en las empresas. <www.ulima.edu. pe>. [Consulta: enero del 2010.]
Kant, Emmanuel (1964). Cimentación para la metafísica de las costumbres. Buenos Aires: Aguilar.

KordA, Michael (1977). El poder. Cómo conseguirlo y utilizarlo. Madrid: Pomaitre.

Maturana, Humberto y Bernhard Pörksen (2005). Del ser al hacer. Los orígenes de la biología del conocer. Santiago de Chile: Comunicaciones Noreste.

Melloni, Xavier. El diálogo interreligioso: Criterios y perspectivas pastorales. <http://www.marti-codolar. org/441_07_Melloni_cast.pdf $>$. [Consulta: marzo del 2008.]

RAE. Diccionario de la Real Academia Española. <www.rae.es>. [Consulta: enero del 2010.]

SAAvedra, Alejandro (2006). Nueva educación. Humanización, globalización, interculturalidad, posmodernidad, medios de comunicación social. Quito: Abya-Yala.

SAVATER, Fernando (2003). El valor de elegir. Bogotá: Ariel.

- (1997). El valor de educar. Barcelona. Editorial Ariel. 